had numerous opportunities of studying the phennmena in that and the adjoining states of Oregon and Nevada ; more especially in the southern parts of the desert. There they are developed on the largest scale, and there their origin is obvious.

Prof. Le Conte's account of them wants but a single word to have settled the question. I attributed them, then, exclusively to the action of the wind, and after reading what others have to say about them, see no reason for changing that opinion. The Professor says, "I attribute them to surface erosion." Had he inserted aërial, nothing more would have been wanted ; although, since he speaks of weeds and shrubs taking possession of thern, subsequent to their formation, he does not seem to have exactly hit on the rationale of the process.

One case may serve as an illustration. In the southern end of the Reese River Valley, Nevada, is a broad, perfectly level plain without a water-course; only a few shallow dry gutters show where the rain water runs to scattered spots, where it sinks or evaporates. The region is almost rainless. The plain is covered for many square miles with these mounds, varying up to four or five feet high, and up to twenty, thirty, and even perhaps forty feet in diameter. In every case they are m ade up of only the finer particles of the soil, the coarser grains and gravel being visible in the interspaces. The dust and sand has in all cases been beaped up in and around a clump of sage bush which continues to grow out of the top of the mound. Little vegetation grow's on the flanks of the mounds, and when it does, it forms the nucleus of a subsidiary hillock. The mounds are thus formed by building up, and only the intervening spaces are caused by an erosion, taking place to day, and not caused by water, much less by ice.

Puerto Plata, Sto. Domingo, June 5

\section{Fertilisation of Salix repens}

DURING May I was watching the movements of the insects on a plant of Salix repens, when I noticed some facts which may prove interesting to some of your reaclers. It was mainly visited by the common hive-bee (Apis mellifica $\Varangle$ ) and the humble-bee (Bombus terrestris + ). The former of these flew gaily about from catkin to catkin merely taking one bite at each; but the latter went far more systematically to work; it never flew at all, but crawled in a ludicrously feeble way from catkin to catkin, and once on a catkin it cleared it thoroughly, thrusting its proboscis between every pair of forets. I do not know whether this greater thoroughness is at all times characteristic of the humblebee as compared with the hive-bee and should mucin like to be informed. And another thing which I do not understand is, that one of these humble-hees appeared to have two kinds of pollen on its legs, one that of Salix repens, the other of a much darker and more-orange colour, though when examined under the microscope the grains proved to be of the same shape. H. H.

Wellington College, Wokingham, June $30^{\circ}$

\section{THE FUTURE OF SANITARY SCIENCE- POLITICAL, MEDICAL, SOCTAL}

I COULD have wished it had been in my power on the present occasion to produce one of those essays which appeal to the imagination while they prepare the mind for the reception of sanitary principles and practice. Such essays are tempting and, in their place, instructive. Today $\mathrm{I}$ am bound on a voyage less pleasant, yet I hope not less useful.

There has recently been called into existence a new society under whose summons we now meet. The society has assumed to itself the expressive name of the Sanitary Institute of Great Britain. It starts as a voluntary effort by men and women who are willing and anxious to give effect to those teachings of sanitary science which the past half-century has revealed. It invites all who

I An address delivered before the Sanitary Institute of Great Britain at the Royal Institution, on July 5, x877, by Benjamin W. Richardson, M.D., the Royal Institut are concerned to utilise the knowledge that has been acquired in that time. It wishes to encourage new research. But it has for its most anxious care to render useful to mankind at large the accumulated store of knowledge which at this moment lies ready for so many grand purposes relating to health. It accepts as its object, work for health, health of all the human family.

Shall some one say the object is ambiticus? Yea, we reply, it is confessedly ambitious. Shall some one say the means at command for the work to be attempted are weak? Even so. Life is short, art long. Yet the short yields the long, and but for the short the long could not be. It is out of these littlenesses of human effort that the greatnesses follow. Or, as Benjamin Rush very forcibly puts it, and simply as forcibly: "There are mites in science as well as in charity, and the ultimate results of each are often alike important and beneficial."

It is my fortune, good or bad, to have to preside over the council of this new society. Of the ability of those who form the council, and of their experience, I need not speak in detail, for their names are familiar to the world. They represent, I may say, sanitary science in all its branches, and from them, working harmoniously together, good results must be expected.

It seems fitting therefore as we enter on our work to look forward to the future. It is a part at least of our duty to look towards the future with the view of seeing in what directions we may best proceed; what assistances we may have to call upon; and chiefly what great powers we may have to consult and propitiate.

The three great powers with which our society will have to treat are the political, the medical, the social. From each of these we shall expect constant assistance. To one or other of these, whatever we do, our work will be transmitted or transferred. They will bring it into practical form and effect, or they will reduce it to nothingness. We can suggest and set forth initiatives, and with that our functions are complete in each particular branch to which we address ourselves.

It is our special duty to keep this special fact steadily in view and to limit our labours by it. It too often happens that young societies like young men are apt to believe that they can conduct national processes as easily as they can conceive them, and under this belief fail most signally with the best of attempts. I remember in my early career getting a lesson from one of our late well-known statesmen on this very point. I was explaining to him the efforts I had made in 1855 and the succeeding three years to establish a registration of the diseases of this kingdom, and I bewailed the hard experience which proved that the greater the scientific success of the effort the more impossible it became to carry. it out. In fact, said I, in a pitiful strain, the success almost ruined me in mind, body, and estate. "Served you right," was the immediate reply, "Served you right. If individual men could carry out national projects where would be the nation?" The reply was hard as it was unanswerable, and from that time to this I have given up all thoughts of doing more than sowing seed in the field of literature and leaving it to the chance of fructification on that extensive soil ; or in showing some mere model of experiment which, perchance, may grow into working form. And this, I think, is the whole natural scope of our Institute,--to sow the 
seed of sanitation; to think out plans of projects for working methods; to lend its many minds, as if they made up the mind of one man, for devising from the past the best for the present, and respectfully to declare our conclusions.

The directions in which we shall have to move, the lines on which we shall have to move, are, I repeat, chiefly three-the political, the medical, the social. The powers on these lines must be approached in every work of ours, however simple, however complicate it may be. I shall try, as the title of my discourse explains, to indicate certain points in which we are most likely to come in contact with these powers and the changes we may expect to work in and through them.

\section{The Political Part.}

In this country political action has been varied in relation to sanitary improvements. Sometimes political necessity has crossed sanitary progress, as, for example, in the imposition of a tax on sunlight, on foods that are essential to life, and in the granting of licences for the sale of pernicious drinks. At other times, and by fits and starts, political action has been in aid of sanitary work. So far back as the reign of Edward the Third, $136 \mathrm{r}$, a royal proclamation was made through Parliament for preventing the slaughter of cattle in the streets of London because of the pollution of the streets and the drains which arose from that cause. Froin that time under great emergencies other similar acts came into force. They rarely lasted very long. As the urgent necessity for their existence passed away, they were allowed to fall into abeyance, and no permanent machinery was kept in order for insuring their continued and effective action.

Let me not, however, in saying this, be understood as conveying any special charge of neglect against English levislation. It is just to state, as an historical fact most creditable to our national history, that our legislators have by a long precedence taken the lead in sanitary affairs over those of other nations. In 1802 the great sanitary act for regulating the labour of children in factories set the example fiom which much useful legislation has followed at home and abroad. In 1838 that great original sanitary scheme for the registration of the births and deaths of the kingdom was inaugurated, to become a collection of facts relating to life, and disease, and death, of which there is elsewhere no parallel. And, since the era of the Crimean campaign, so much legislation has been attempted bearing on health, I dare not attempt even to enumerate the titles of the cifferent measures that have been introduced. At this moment there can be no doubt as to the sincerity of our governments, of whatever party they may be composed, for dealing with every subject relating to the public health in an efficient manner, and in as rapid a progression as the slow and sure mode of parliamentary procedure will permit. The subject indeed presses at this moment with so much force on the governing mind, that if there be any danger ahead it is the danger of too miraculous a draught of small enactments, to the exclusion of comprehensive measures which all who run may read.

In saying this it is necessary to guard myself against error of expression. By comparison with all the nations of the world beside, we have obtained legislative measures which are splendidly comprehensive. No other country in the world can present an approach to the Public Health Act of 1875. That Act, as far as it goes, is admirably constructed. Its constitution of sanitary authorities throughout the kingdom; the power it vests in those authorities to appoint learned medical officers of health ; the provisions it makes for securing to each locality better sewerage, freedom from nuisances, improved water supply, regulation of cellar dwellings, governance over offensive trades, and removal of unsound foods; the provisions for prevention of spread of infection and for the erection of hospitals and mortuaries; and the provisions for the regulation of streets and highways, lighting of streets, establishment of pleasure grounds, and regulation of slaughter houses; these, as well as the general provisions for the carrying out of the Act, are most commendable as practical plans by the working of which the nation may be tempered into sanitary mould of thought and character.

In a word the Act of 1875 is an improvement of the first degree on all that has preceded it, and although much of it, by the necessities of the constitution of our country, - which recognises the domination of free will even in its age of ignorance,- of a permissive nature, the working of the Act must in a few years remove a great amount of disease from the land and prevent the invasion of diseases of an epidemic and spreading type.

Sanitation however admits of being studied from two distinct points of view, the legislative and the scientific. The legislator may say, and perhaps with justice, that the production of such a measure as the Act of which I now speak is as much as can be done. The man of science may say that this is childish talk, that much more requires to be done, and that after all that which has been done, though it be comparatively great, is practically imperfect and very little. Science in this respect is always in advance of legislation, and that is her true place,-the pioneer's place. I remember the time perfectly when every fragment of the Public Health Act of 1875 was in the hands of men of science solely, and was called a chimera, over which great lawgivers shook their wise heads and passed by.

At this moment the positions of science and legislation are relatively the same as they have ever been, and it is fair for us men of science now as in the past time to declare the way ahead for the law-maker. I shall proceed again, therefore, as I have often before, to indicate one or two new starts in sanitary legislation, not from the legislative but from the purely scientific point of view, uninfluenced by the many and vehement individual grievances and troubles which beset the path of the minister of state. In so doing I shall indicate also, by inference, what I think our society ought to support in the sanitary policy of the future.

In the first place, then, we ought to expect in the political progress of sanitation that there will be established in connection with the Government one central department in which every subject, directly and even indirectly, connected with the health of the people, will be considered. This department, it is to be hoped, will be under the control of a Cabinet Minister, and will supervise the sanitary work performed at present by the Local Government Board, the Registrar-General's department, the sanitary regulations of jails and reformatories, and all the duties now pertaining to the supervision of factories, in so far as the health of the employed is concerned : in fine, every sanitary work that can be weeded out of every other department of the state.

To such a central board or department a specific name is necessary. The name should be as distinct as that of the department for war, for the navy, for the exchequer, or for the post-office. The name, it is to be hoped, will be emphatically the Health Department, and the chief of it the Minister of Health.

It may be urged that substantially we are drifting into some such order as is here suggested. It may be urged that the Local Government Board is step by step assuming the duties assigned, as above, for the State Department of Health. To some extent this is true, and it might be advisable, for the sake of the connection which must 
always exist between such a central board and the various local boards, in the kingdom to add to the name of Health Department that of Local Government Board. But for the sanitary object the leading name must be Health, and Local Government must come in merely as indicative of the connections that exist between the State and the local centres-as the machinery.

In this question of progress there is involved an immense deal in a name. It is essential to the scientific sanitary teacher that every reasoning mind in the kingdom should become familiar with the two significant words, public health, or national health. It is equally necessary to let the people know fully that the Government has the health of the country under its general and wise supervision. But it is utterly impossible to make either of these facts understood by the masses so long as any sanitary authority, central or local, has a title which fails to convey the meaning of its functions. To speak to the masses who are listening to a lecture or discourse on health about a local government board is only to confuse them. They ask you afterwards what it all means, and they go away imbued with the impression that it means anything except what relates to the health of the people.

I am speaking very practically in suggesting that in the course of political sanitary progress it is an absolute necessity for success to give its proper and only name to the department of state which presides over the national health. I do not state too much in declaring that every public measure would carry more weight if it went forth as being under the supervision of the health department. It may appear a refinement of illustration, and yet it is a sound argument that vaccination would have met and would meet with far less opposition if it were enforced under the general supervision of a State department of health. As it is the people connect the carrying out of vaccination with something other than health, and even as distinct from the idea of conservation of health. It is looked upon as a legal tyranny, having no scientific setting forth of its intention, and as springing from no scientific authority. If you attempt to reason with its active opponents on the subject, and refer to the authority that exists, they dispute the competency of the authority in name and form; and, foolish as the objection may be, it is potent for obstruction.

In making this suggestion there is no necessity to offer a word against the continued action of local self-govern ment. The work of the local centres in all parts of the kingdom instead of being in any degree curtailed and restrained, should be encouraged and maintained. In the sanitary local work the word health should, however, again come forward as the one prominent designating term to which all others should be subject.

Our Sanitary Institute could not turn its attention to any more suitable labour than that of inculcating the necessity for the institution of one state department exclusively devoted to the health of the people. In the success attending such an effort a double result would be achieved. The country would have secured for it the best and most direct guidance on its most vital interest, and scope would be given to the industry of men of science in a new direction. Men, whose lives have been devoted to the study of life and health, would be prepared by their devotion for the accepted service of their country in public form, and the Houses of Parliament would become, at last, congenial spheres for their labours. The Houses would be strengthened by such adhesions; the men would be more useful and honoured.

Another work in the political line which will be demanded in the future for the benefit of the sanitary cause is the preparation of such a digest of all our practical sanitary laws that every person of intelligence can read and understand what may be legally enforced for the maintenance of health. What may be done in this direction ought to be so simple and so plain as to be brought into a scheol-book. Not a line should be left for the subtlety of the legal brain to twist into contortioned illegibility. The laws by which the health of a man, and thereby of a nation, can be preserved to the utmost, are so simple in nature that nothing but the utmost simplicity can truly express them, and the whole labour of the future, if it is to be of any service whatever, must be directed to the discovery and establishment of such simplicity of exposition and direction. Up to the present time much that has been done has been provoked by that most untrustworthy of all human provocatives to action,fear. Some great epidemic has occurred that has caused universal dismay; some great catastrophe has occurred, like that of the Crimean campaign, which has excited universal criticism on the failure of sanitary provisions by the authorities of the nation. Some such slip has been permitted in sanitary rule as that which recently let scurvy undermine the workers during a great enterprise of discovery. Straightway on the beels of such events there have been commissions of inquiry, and as a direct or indirect result there has often come forth some particular enactment. Or - and this is by no means rare-some individual of the House of Commons, impressed with the danger of a great national evil, has pressed for a national remedy, and, by steady persistence session after session, and by showing that he never knows when he is beaten, has forced the Government to take up his measure and to carry it through.

From these modes of legislating for health we have obtained many minor acts which fill and refill the national statute books. And still this process promises to go on, a process of labour in a circle with much loss of time and expenditure of force without uitimate progression.

It would be vain to find fault with the past for its doings. As vain to find fault with the State for meeting State disorders by empirical remedies as it would be to find fault with the physicians of a former day for the same mode of procedure. If the people dernand a recipe they must have it, be it from the State or the family physician. The question that now comes forward is whether the time has not arrived for ceasing to treat the health of the nation by specific or supposed specific remedies for particular errors, and whether we may not find in the future a few very simple and natural guiding principles on which all acts of Parliament relating to the health of the people may be based?

Before this effort can be attempted the existing acts that touch on health,--public health acts, metropolitan health acts, contagious diseases acts, vaccination acts, factory acts, acts relating to the importation of cattle, adulteration acts, and others relating to prisons, workhouses, and the like, and which, if they even lie latent are not repealed,-these, one and all require to be considered together, with the view of determining whether an English or even a British act of settlement for the vital regeneration of the realm is not practicable on a simple natural basis of natural requirement.

I am fully aware that this suggestion carries with it the idea of a gigantic labour; but it will have to be done, and once fairly tackled I dare say the apparent difficulties will readily dissolve away. It is a mere question between doubting and attempting: and we all know and feel that-

$$
\text { "Our doubts are traitors, }
$$

And make us lose the good we oft might win By fearing to attempt."

Supposing the existence of an efficient central department of health acting under the direction of a minister of health, a grand new duty, as it seems to me, would be to determine what is the evil or what are the evils that have to be removed in order that the cleanest bills of health may be regularly presented to the nation. Without such preliminary knowledge all sanitary work is unsound to the last degreẹ. It were as wise for me to 
write a prescription for a man without inquiring into his disease, his antecedents, and modes of life, as for the State physician to prescribe for national sickness without inquiry into the nature of the sickness, its antecedents, and the cause or causes that led up to it. The great work, therefore, and indeed the first sanitary work of the future, standing before all other sanitary legislations except the formation of the central authority, is the systematic enumeration, week by week, of the diseases of the kingdom, through the length and breadth of the kingdom. It is utterly hopeless to attempt any decisive measure for lessening the mortality, which is certainly more than double what it ought to be, until this State labour is faithfully carried out. It is vain, comparatively speaking, to know what totality disease hands over to death, unless we know also what health under one or other cause of disturbance yields over to disease. Physicians and statists strain their eyes to try to get at the extent of discase. Laborious geographers like Mr. Haviland spend years in constructing maps from the tables of mortality, in order to get a mere approximation of the distribution of disease in England: and meanwhile disease itself, constantly cheating the observers, is making its way without being under any systematised recorded observation.

For the omission of a registration of disease there is no conceivable excuse. The thing has only to be done. The organisation of the Registrar-General's department has fully opened the way to the collection and the utilisation of the facts relating to birth and death. These elements swing in the statist's balance readily, and are weighed by our consummate state weigher of life and death, Dr. Farr, as accurately as the Chancellor of the Exchequer balances the national ledger. With equal readiness Dr. Farr, if the data were collected for him, could tell from week to week the health as well as the mortality of the kingdom. In a short time, under such regular record, the whole nation would know the reigning health, the reigning disease, of every centre of life. And if, as might easily be done, the diseases of the lower animals and the diseases of the vegetable kingdom were included in the returns, all the facts of disease would be completely rendered.

I think I have already referred to an effort I made many years ago to carry out this design of registering the diseases of the kingdom. I refer to that effort again for a simple reason,-for the purpose of indicating that there is really no greater difficulty in getting the facts than there is in utilising them. I attempted no more than the registration of the epidemic diseases, and I could afford no more than the publication of a quarterly abstract of the data that were forwarded. But in a short time fifty medical observers were sending in returns from as many stations, extending from St. Mary's, Scilly, to Lerwick, in the Shetland Islands. These stations could easily have been increased to any extent, and the amount of information regularly communicated was indeed most valuable.

Two facts connected with this attempt are perhaps worthy of note, one as showing something determined, and the other as showing something suggested. In the returns sent from the district of Canterbury in the spring quarter of the year 1857 was included the first account of the invasion of this country, at least in any known time, by the disease since then so prevailing and fatal, diphtheria. This disease first appeared in the little village of Ash, and was called the Ash fever. The outbreak was observed and recognised by Mr. Reid, of Canterbury, and was reported to my register by $\mathrm{Mr}$. Haffenden, who collected for me the facts of prevailing diseases from eight medical observers living near to him, of whom Mr. Reid was one. The first facts of a new disease in this country were thus recorded on the spot, which is something even as matter of history. How such a fact, reported at once to a central government authority, might be dealt with; how promptly a central authority so advised might act in arresting a fatal epidemic at its origin, and what national service might be rendered thereby, you, quite as well as I, can judge !

The fact of a suggestive nature springing from the working of the returns is not less interesting. The labour led me to refer to the returns of sickness sent every week by the medical officers of the Poor-Law districts to their boards of guardians. I found that these returns, over 3,000 in number, which, when they have served their local purpose, are practically worthless, could by the slightest modification be utilised as returns of the sickness of all the sick parochial population under official medical care, and I submitted a plan for such introduction to public approval and to the Government, but without effect. Yet if the plan had been adopted from those three thousand weekly returns, cast away and still cast away, I calculate that i 56,000 tables of disease per year would have been submitted to scientific analysis which, since the time when the suggestion was first made, would have multiplied into $3,276,000$ tables, including in each table a record of at least ten times as many particular examples of disease. To what important national uses such an array of facts systematically arranged and examined could have been applied you, as well as I, can judge! And still neither of us can judge effectively, because in dealing with data taken from nature there is always something important to be elicited which never was looked for, and often, too, that something unlooked for is better than that which was specially looked for.

Our Sanitary Institute will do well in continuing to press this scheme for the registration of disease on the Government, and it may greatly assist the work by lending its mind to the best means of collecting the facts on which the weekly reports of disease will have to be bised. I might enlarge on this part of my subject, but I shouid prefer to remain silent until the views of the medical officers of health, now a large and influential class, have been correctly ascertained. My present purpose is served if I have sufficiently directed public attention to the principles of the design.

In the future of sanitary science the politician must come forward more determinately than he has yet done, in order to secure for those over whom he governs three pure requisites-pure water, pure food, pure air.

The Public Health Act of 1875 deals with the water question, and makes provisions for the local authorities to supply their respective districts, by means of a company, or by independent action. For my part I see no hope of any effective change for the better by these propositions. It is utterly hopeless to trust to companies in a matter of such vital moment. It is equally hopeless to trust to the undirected action of local authorities. If we trusted to such agencies for the collection and delivery of letters by post, does any one suppose that the resuits of our present postage system would be attained? Yet important as intercommunication by letter is, it is less important than the supply in due quantity and pure quality of that vital fluid which makes up three parts out of four of every human organism, and which is wanted as much by the millions who never receive a letter, as by the millions who do. In this political part of sanitation, the Government must do one of two things. It must either produce a process or processes for pure water supply, and insist on every local authority carrying out the proper method; or it must,--and this would be far better,--take the whole matter into its own hands, so that under its supreme direction every living centre should, without fail, receive the first necessity of healthy life in the condition fitted for the necessities of all who live.

By recent legislation we have some seiurity for obtaining fresh animal food, and foods freed of foreign substances or adulterations. The penalties that may be inflicted on those who sell decomposing, diseased, or adul- 
terated foods are beginning to have effect, and much good is resulting. Nevertheless, even here the legal rule falls short of completeness. The inspection of animal food is as yet most unsystematic and imperfect. With all our richness of means ready at command, we have not approached that admirable system for the inspection of animal focds which our Jewish brethren, through ages of ignorance and oppression, have managed so efficiently to carry out, and which bas entirely saved them from many of the great calamities of disease that have fallen on less careful people. The complete inspection of animal foods, including milk, is a clear piece of sanitary law which, from day to day and hour to hour, must ultimately be enforced.

Imperfect as legislation may be in respect to supply of pure water and food, it is advanced in these directions when the steps it has taken for supplying pure air are brought under observation. There is no practical legislation of any kind on this requisite. The air of our large towns is charged with smoke and impurity. The air of our great factories is charged with dusts which destroy life with the precision of a deadly aim. Dr. Purdon, one of the certifying surgeons under the Factory Acts, reports that in the flax-working factories under his care the carders, who are all females, if they get a carding-machine at eighteen years, generally die at thirty years. Can any fact be more terrible than such a fact, that a girl of eighteen should have to live by an occupation that will bring her existence to an end in fourteen years, and to that end with all the prolonged wasting, sleeplessness, suffering, incident to the disease consumption of the lungs. If it were the fate of these doomed workers that at the close of fourteen years' work the majority of them were taken forth and shot dead in an instant, their fate were infinitely better than it is. The heart of the nation would thus be roused, and the law in all its majesty would be put in operation to arrest the progress of the crime and to punish the offenders. Yet, year after year as effective an offence goes on, and because the results of it is hidden in the sick-room there is no arrest of its progress, no punishment for its commission.

In the application of political science to preservation of health not one subject presses more earnestly than the question of the supply of a pure atmosphere to the millions of industrials of these islands. In an inquiry I recently undertook on this matter for the Society of Arts, Manufactures, and Commerce, the facts that cane before me were as of a new world. You will find a compact mass of these facts in the lectures $I$ had the honour to deliver before that learned society. Those lectures contain a tithe only of the things seen. I am quite sure that our leading politicians can have no ade quate conception of the mental and physical condition of the great industrial classes, or of the need that exists for reconciling those classes to their fate. These truths are plain.

The catechism has failed to satisfy them. Bad air keeps up in them a depraved mental as well as physical state. Their poverty and not their will consents to their condition. In short, as a physician dealing with the physiological and psychological phenomena belonging to a class instead of an individual,- and this is all the difference there is between a politician and a physician, - my diagnosis is that a serious organic state febrile, fitful, fatal, exists in this part of the nation; that it demands the watchful consideration of all physicians, State and ordinary; and that the sooner the natural cure for it, pure air, and plenty of it, is let in the better for every class everywhere.

All political troubles have a physiological cause. To the Statesman not less than to the physician, physiology is the only true source of knowledge. A society such as ours, therefore, possessing as it does professed physiologi- cal skill, may render most important service by tracing out for the legislator the simplest scientific means for removing with atmospheric impurities and by preparing for that sanitary future when men universally shall breathe purity even with their freedom.

If any other incentive to action in this direction were required it would be the further fact that all diseases, mental and physical, national and individual, begotten of an impure atmosphere, are transmitted on. The consumption of body, the restlessness of mind are reproduced and gain intensity of development with each generation until practically they inaugurate a distinct racial type of human imperfectedness.

With this topic of legislating for pure air would come in naturally the question of homes for the people and the development of those recent acts which have been passed to meet the necessity. These efforts of the world political can scarcely be over-estimated; but there is one movement which stands before them and which has been singularly overlooked. It is essential that the home of the working man should in every case be cleared of the details of daily work. So long as he is compelled to work in the room in which he sleeps and takes his food, so long his home must be an unhealtby centre, and too often it will be the centre from which infected work will pass out, bearing infection into the homes of the wealthy. A modification of factory legislation by which a free and properly regulated work-room should be within the easy reach of every working man in every crowded centre is a necessity which all sanitary labourers should strive to get supplied. Our Institute has another urgent task before it in the effort to enforce this necessity on public attention.

In the future of sanitary science one more amongst many other reforms of a political character must needs claim important consideration. I refer to the political assistance that must be given to all of us who are engaged in the labour of quenching the drunkenness of our land. Our best sanitary efforts will fall far short of their deserts until this object shall be achieved. Over the future of sanitary science will be suspended a pall of sorrow until this object shall be achieved. Does any one desire to know how the mortality of the kingdom is modified by strong drink, let him read the knowledge in the State record book which tells that those who sell the destroyer die by it at the rate of one hundred and thirty-eight to the hundred of the whole population. Then, starting from this signal fact, let him trace the influence of the destroyer through all the courses of diseases which, under learnedly obscure names, spring from it and kill from it in all classes of society. Finally, let him reckon up the hereditary evils which are engendered by the same destroyer and the infiuence of that on the course of disease, and his lesson will be in some measure complete.

I do not think this the occasion to discuss the value of the different political sanitary measures that have been, or are at this time, in the public mind for the repression of the national evil now touched upon. Be it sufficient for me to state two impressions only. Firstly, that every day's experience of the question in various communities where as a teacher of abstaining temperance I am wont to labour, indicates to me that unless the State does come to the aid of the teacher the battle against intemperance must be indefinitely prolonged. Secondly, that if the State, itselt doing nothing active in the way of repression, would but determine to cease to legalise the cause of the evil and to make revenue out of the transaction, the labours of the temperance reformer would have the most prosperous season of success presented to their view. Hitherto this has not been considered as a sanitary question. In the future no sanitary student will venture to exclude it from his studies.

The contemplation of the political sanitary future of this kingdom offers many other topics, all of which I must 
leave, in order to devote a few minutes to our subject in its relation to medical science.

\section{The Medical Part.}

The influence which sanitation will exert in the future over the science and art of medicine promises to be momentous. It promises nothing less than the development of a new era; nor is it at all wide of the mark to say that such new era has fairly commenced. The greatest of the world's philosophers, the philosopher whose thoughts cover the world of science as with a garment, I mean Lord Bacon, said of the medicine, of his day, that it stood for judgment on quite different merits than did other learned pursuits. "Other arts and sciences," he argued, "are judged of by the power and ability exhibited in the conduct of them by their professors, and not by success or by events. The lawyer is judged by the skill of his pleading, not by the issue of the trial; the pilat by his skill in directing the course of the ship, not by the fortune of the voyage. But the physician can perform no particular act by which his ability can be directly demonstrated, and therefore he is principally judged by the event, which is very unjust. For who shall decide, if a patient die or recover, whether the good or the evil is brought about by art or by accident? Whence," says he, "imposture is frequently extolled, and virtue decried. Nay the weakness and credulity of men is such, that they often prefer a mountebank or a cunning woman to a learned physician. So the ancients made Esculapius and Circe brother and sister, and both children of Apollo. Hence," he adds, "physicians say to themselves in the words of Solomon, 'If it befall to me as befalleth fools, why should I labour to become more, wise?' And therefore one cannot wonder that they commonly study some other art or science more than their profession, because they find that mediocrity and exceilency in their own art makes no difference in profit or reputation; for man's impatience of diseases, the solicitude of friends, the sweetness of life, and the inducements of hope, make them depend upon physicians with all their defects."

Had Bacon spoken these sayings in the present day, he had spoken, with nne or two exceptional errors, as truthfully as he spoke in his own time. Had he been a physician, he might indeed have gone further than he did. He might have urged his too frequent inadequacy himself to decide whether his own success- rested, in particular instances, on skill or on accident. He might further have added how oftentimes the cheek of the right-minded physician pales or burns with doubt as he hears his own praises declared for skill which he himself cannot for a moment take credit to his own heart. This has been the fate of medicine until our day. On such fate all the quackeries have flourished; on it all the "pathies" and dogmatic systems of medicine have flourished; on it the idea of cure has found too willing acceptance and belief.

At last a change has come over the science of medicine. With true nobleness of purpose, true medicine has been the first to strip herself of all mere pretences to cure, and has stood boldly forward to declare as a higher philosophy the prevention of disease. The doctrine of absolute faith in the principle of prevention indicates the existence of a high order of thought, of broad views on life and health, of diseases and their external origins, of death and its correct place in nature. The doctrine of absolute faith in curative medicine, of power vested in the hands of a distinct sect or class, and exercised by them as by regal right and without the assistance or interference of those upon whom it is exercised, indicates a low standard of knowledge; a too confiding spirit in the wisdom of a minority; a departure too wide from the safe law of self-preservation; and an ignorance of the avoidable causes of diseases ; a blindness and therefore an unnecessary exposure to danger; an overweening and sudden fear of dangers of all kinds little and great, and a hasty and thoughtless pursuit after that mode of rescue from dangers of disease which claims for itself the greatest pretensions and boasts the greatest successes.

It shall remain as one of the glories of medicine that she herself has first seen these truths, and, willing to sacrifice her own interests to truth and light, has put them forward without fear, without reward. In the science of prevention medicine takes in fact all the world with her. The science becomes a political, a social, as well as a medical study. It appeals to every mind. When it once is so set forth it fills all men with its teachings. It models itself into household truths and commingles with the moral and even religious elements of life. Admitted for a season into the household, it steps forth again to find its way into the legislature. It becomes eventually a governing science-a law.

This scientific course commenced, must needs go on. But in its going it must needs also change greatly the old face of medicine, and remove in the change the Baconian reproach. I do not think there is much difficulty in foreseeing what in the main the change will be like.

I need not say that the "pathies" will go. The pathies of all kinds are as dead as door-nails, and wait only to be decently interred in a common grave. In time the word cure will go altogether. It is clear already that there is indeed no such thing. A man born to live through a given cycle lives through it free of disease, unless he be stricken from without. If he be stricken, and by the stroke the natural functions, by the exercise of which he lives, are not so disturbed but that they can swing back again in due order, he may recover; if he be stricken beyond this, he will die. Nature will pursue her course undisturbed by either event. She will make no special effort to kill, and assuredly she will put out no special hand to save. A man may intervene, and may, by knowledge, put the stricken body into such a condition that it may swing back into natural course whereby he will have put it into a condition in which it will not die. This is the very highest development of medical art resting on science. But it is not cure, in the common meaning of that term.

By the progress of sanitary science and by its influence on practical medicine we shall attain these perfect rules of management after the infliction of the stroke of disease; and I do not doubt that the art of placing the stricken under such conditions that they may not die will for ever afford scope for the inventive genius of man. The more immediate triumphs will, however, come in that part of the work which is purely preventive. Down from the skies comes the forked lightning and lays a man prostrate. It is a question for the ages who shall place that man in a condition under which he shall certainly swing back again into life. But the preventive art that puts up a metallic rod to divert the lightning from other rnen, that is the present triumph of human skill; skill which, carried to perfection, shall prevent the stroke and put out the second art by removing the necessity for its application.

With the progress of sanitary science we must expect to see preventive medicine taking the ascendancy. Cure will cease, prevention will grow. Humanly-made epidemics, like the great plague of London, which was planted and reared in the rush-covered floors of domiciles saturated with the organic refuse of years, or like the modern typhoid, which is fed by streams of drinking water uncleansed from human excreta, such self-made epidemics will be prevented by simple mechanical skill. Diseases imposed by indulgence in harmful pleasures and appetites, or by physical overwork and shock, will be removed by the effect of moral influences and knowledge of cause ; and gradually, I believe, those persistent evils, which, like the lightning-stroke, come without human ordinance or fault, will be placed also under some pro. 
tecting care, and, if not removed, reduced to a short calendar.

It is felt by some that the medical Sanitarian of the future will have his best efforts thwarted by the forcible excess of life beyond the means that can be found for the support of life, as if life were a mere secondary principle in the universal order. I see no such cause for fear. That in the progress of life on the earth the day will ever come when the earth will not supply food for its people is to my mind pessimism carried into an insane vulgarity. It is clear that man can always reduce to his wants the lives of all animals except man. The question rests therefore on the abnormal increase of man alone. Nature knows that and rules accordingly. Let man remain savage, and, however sensual he may be, he will die fast enough by war, plague, famine, or luxury. In that state he will never overstock the earth, but either grope in solitary places a neglected family, unprotected from all the killing vicissitudes, or will sink into luxurious barbaric decadence. Let man become exalted in life ; exalted by communion with noble pursuits ; with pursuits of science, art, letters, and cultivation of greatest happiness for the greatest number, and his sensual life will become too subject to the virtue to leave a chance for the danger which a low sensuality sets up as a terror and at the same time a temptation for the vulgar.

I think it my duty to deal plainly with a question which affects so closely the future of sanitation, and to express, from an experience which is confirmed, as I know, by some of the brightest ornaments of my learned profession, that nothing is wanted to correct the danger of overpopulation but improvement of mental process; nearer communion with the eternal mind in $\mathrm{H}$ is works; purer artistic education, healthier homes, more rational amusements, and the ennobling influence of a holier life amongst those who assume to be the cynosures of the nation.

On the whole the prospects of medical learning and action will be greatly improved by sanitary advancement. It is possible that fortures or reputations resting on faith in famous curers will dwindle slowly away, and that not for long will the skill of the physician be valued by the fa!lacious reckoning of mere results. But in exchange there will be opened to the physician a career in which skill of labour will be exhibited together with results, the results obvious as to their relation to the work, and both, if good, successful beyond praise.

\section{The Social Part.}

The future of sanitary science in relation to social life generally, its effect that is to say on all classes of the community, promises steady progress. No one who has been actively engaged for the past quarter of a century in sanitary work can doubt this statement. Throughout all sections of the community there is desire to know; and if the legislator will be content not to legislate until he sees that free-will guided by knowledge is in the same train with him-it doesn't matter in which class, -all will go well. The workers in our Sanitary Institute though they be not legislators can, nevertheless, greatly assist Parliament by bringing free-will into harmony with knowledge, and though the distinction does not at first sight stand out, in separating free-will from ignorance and from those automatic demonstrations of ignorance which are the outward and visible signs of unhealthy habits of life.

The social work that has to be carried out for the future of sanitary science is purely educational. Educational not merely by lectures and books and lessons from books, but by demonstrations of sanitaty works, plans, buildings, mechanisms, results of all labours bestowed on the cause. Without venturing on details of this kind which would land me in another address, I may be content to touch on two points, both of vital moment for the future.

The first of these relates to modes of teaching so as to carry the sympathies of the learner and his more refined tastes along with his reason ; to attract and charm his senses as well as his intellect. It is said of us sanitarians, and sometimes I fear with some truth, that we would make health hideous. We need not do so; and if the feat has ever been accomplished it is but the work of a "prentice han," that ought to be forgiven. Health truly is beauty in the living evidences of it, and should be so in those inanimate evidences which the builder and the engineer construct for us. I would therefore urge that in all coming sanitary work, theoretical or practical, the sanitarian should call the artist also to his side, and that no design of a sanitary kind should ever be executed in which the hand of the artist does not play its beautifying part.

And if I might suggest so much to the imaginative scholars who live to make life sweeter to the many, I would ask them,--poets, painters, sculptors, players, musicians, - to believe that to render practical even their refined labour is to render that labour more acceptable, more diffusible, more durable.

The second topic relates to those who require first to be taught the sanitary lessons of the future. I want strongly to enforce that it is the section of the nation which Dr. Farr classes as the domestic, the six million of women of the nation, on whom full sanitary light requires first to fall. Health in the home is health everywhere. Elsewhere it has no abiding place.

I have been brought indeed by experience to the conclusion that the whole future progress of the saritary movement rests for permanent and executive support on the women of the country. When as a physician I enter a house where there is a contagious disease, I am, of course, primarily impressed by the type of the disease and the age, strength, and condition of the sick person. From the observations made on these points I form a judgment of the possible course and termination of the disease, and at one time I should have thought such obserrations sufficient. Now 1 know them to bc but partly sufficient. A glance at the appointments, and arrangements, and managements of the house is now necessary to make perfect the judgment. By this is shown what aid the physician may expect in keeping the sick in a condition most favourable for escape from death ; and by this is also shown what are the chances that the affection will be confined to one sufferer or distributed to many. As a rule to which there are the rarest exceptions, the character of the judgment is hereupon dependent on the character of the presiding genius of the home, -on the woman who rules over that small domain. The men of the house come and go; know little of the ins and outs of anything domestic; are guided by what they are told, and are practically of no assistance whatever. The women are conversant with every nook of the dwelling, from basement to roof, and on their knowledge, wisdom, patience, and skill, the physician rests his hopes. How important, then, how vital that they shall learn as a part of their earliest duties, the choicest sanitary code. How correct the decision of the founders of the Sanitary Institute, that from the first they should include sanitarians of both sexes as working associates.

To women more than to men this work is new. To women more than to men this work is hard to realise. Naturally more conservative than men they are moved with less haste to tasks of reformation and reconstruction. More sensitive to criticism than men, they are given, at first, to resent, as if it were an insult to past customs and usages to which they are attached, the suggestion of innovation. But these passing difficulties removed, there is in the hearts of women such matchless generosity, such overpowering love for every device tending to promote the happiness of all things of life, that we sanitarians may indeed be content for the future of sanitary science in its social aspects, if we do no more than win them to our cause and entrust its details to their ministering spell. 